\title{
Perceptions of the impact of depression and anxiety and the medication for these conditions on safety in the workplace
}

\author{
C Haslam, S Atkinson, S Brown, R A Haslam
}

Occup Environ Med 2005;62:538-545. doi: 10.1136/oem.2004.016196

See end of article for authors' affiliations

Correspondence to: Prof. C Haslam, Professor of Health Psychology, Institute of Work, Health \& Organisations, University of Nottingham, William Lee Buildings 8 , Nottingham Science and Technology Park, University Boulevard Nottingham NG7 2RQ, UK; cheryl.haslam@ nottingham.ac.uk

Accepted

18 February 2005

\begin{abstract}
Background: The number of people taking prescribed medication for anxiety and depression has increased greatly, but little is known of how this medication impacts on safety at work.

Aims: To examine the relation between anxiety and depression, prescribed medication, performance, and safety in the workplace.

Methods: The research involved nine focus groups with sufferers of anxiety and depression to investigate experiences of mental health problems and the impact of psychotropic drugs. A further three focus groups were conducted with staff in human resources, personnel, occupational health, and health and safety departments, to explore organisational perspectives. The sample comprised 74 individuals drawn from a wide range of occupational sectors. Finally, the results were presented to a panel of experts from occupational medicine, general practice, psychology, health and safety, and psychiatry, to consider the implications for practice.

Results: Workers reported that both the symptoms and the medication impaired work performance. Participants described accidents which they attributed to their condition or to the medication. Workers with responsibilities for others, such as teachers, healthcare workers, and managers appeared to present a particular safety risk. Healthcare workers believed that they placed themselves and their patients at risk when carrying out medical procedures.

Conclusions: Respondents in this study felt that their symptoms of anxiety and depression and the medication they took to treat these conditions placed them at risk with respect to safety in the workplace. Drawing on the results, the authors outline areas for improvement in the management of mental health problems at work.
\end{abstract}

$\mathrm{T}$ he prevalence of stress and related conditions in the UK is estimated to be double the level it was in $1990 .{ }^{1}$ This increase in stress related ill-health has been accompanied by a sharp increase in the number of prescriptions for psychotropic medication. ${ }^{23}$ It has been noted that between 1991 and 1996 there was a 40\% increase in the prescribing rate of tricyclic antidepressants compared to a $460 \%$ increase for selective serotonin reuptake inhibitors (SSRIs). ${ }^{4}$

Several studies have highlighted the poor knowledge that exists concerning the effects of prescribed medication on work performance. Psychotropic medicines impair performance on a wide range of laboratory measures, with effects found for attention, vigilance, memory, problem solving, and motor coordination. ${ }^{3-7}$ But it is unclear how these effects translate to performance in the workplace. ${ }^{8}$ Problems with generalising from laboratory investigations to the occupational context relate to the fact that laboratory investigations are often limited to young, healthy subjects, and minor decrements in performance on laboratory tasks may have little relevance to real world activities. ${ }^{9}$ Also, laboratory studies usually do not simulate the effects that workplace environments may have on pharmacokinetic pathways or physiological homoeostasis. ${ }^{10}$

With regard to this last point, work can affect both an illness and the action of medication used to treat it. For example, stress may worsen psychiatric illness, shift-work can influence the physiological response to drugs, and heavy work in the heat may lead to dehydration, affecting blood concentrations of medication. It is not clear, therefore, to what extent medication taken for psychiatric illness may affect a person's quality of work and productivity. Perhaps more importantly, very little is known about possible consequences for workplace safety. Mintz et al evaluated the effects of antidepressants and psychotherapy on work performance in depressed individuals from 10 published treatment studies. They found that improvement in work performance lagged behind improvement in psychological symptoms. ${ }^{11}$

A further issue is that lack of treatment for psychiatric illnesses may be a greater problem in terms of work performance than the side effects of medication. Employees suffering with depression or anxiety are likely to experience a range of symptoms that would impair performance at work. Anxiety is characterised by worry, restlessness, fatigue, poor concentration, irritability, and sleep disturbance. Depression involves depressed mood, sleep disturbance, fatigue, poor concentration, thinking, and decision making. ${ }^{12}$ It is widely accepted in the psychiatry literature that depression often coexists with anxiety. ${ }^{13}$ This study therefore investigated the effects of both conditions, as symptoms of anxiety and depression are likely to lead to impaired work performance and an increased risk of accidents.

This research used a qualitative, descriptive approach to collect new and in-depth data on anxiety and depression and the use of psychotropic medication among the working population. A qualitative approach was most appropriate for this study, which attempted to tap into employees' personal experiences of managing mental health problems at work. The aim was to improve understanding of the impact of mental health problems and treatment for these conditions on safety in the workplace.

\section{METHODS}

The use of focus groups

Qualitative research organises and classifies people's descriptions, reports, and comments. It is concerned with the 


\section{Main messages}

- The incidence of psychiatric illness is increasing, and the number of prescriptions for psychotropic medication has sharply increased.

- Laboratory studies have shown that psychotropic medicines impair psychological functioning, but it is not clear how these effects translate to the workplace.

- This study collected new and in-depth data on the impact of psychotropic medication on working people, across a range of work sectors.

- Both the symptoms of anxiety and depression and the medication for these conditions impaired work performance. A variety of accidents were attributed to the symptoms or to the side effects of medication.

- Workers with responsibilities for others, such as teachers, healthcare workers, and managers, believed they presented a particular risk to safety in the workplace.

meanings people attach to their experiences and their interpretation of events. It uses open ended questions to elicit this information and these can be administered in interviews or focus groups.

A focus group is a form of group interview whereby the data obtained arise from the interaction and discourse generated by a group discussion. Topics are supplied by the researcher who acts as "facilitator" for the discussions. The facilitator ensures that certain topics are addressed and encourages participants to express their views and discuss their personal experiences.

The focus group technique was well suited to this study where the research aimed to elicit information about the personal experience of mental health problems and the impact of psychotropic drugs on work performance. Given the sensitive nature of the topic, the focus group method (as opposed to individual interviews) allowed participants a degree of discretion as to how much personal information they revealed. Respondents reported that they were comfortable in discussing their experiences. Indeed, many commented that they welcomed the opportunity to share their experiences with others in similar circumstances. The groups were facilitated by two experienced researchers who managed the discussions with care and sensitivity.

\section{Recruitment}

The research team used a range of recruitment techniques including: liaison with established contacts in organisations; contact with bodies with responsibility for health and safety; contact with trades unions; mail shots, telephone calls, and emails to organisations; advertisements in national and local newspapers, professional publications and local radio; and distribution of posters to organisations.

\section{Research participants}

Twelve focus groups were conducted in total. Nine focus groups involved people with personal experience of anxiety and/or depression in the previous two years and who had taken prescribed medication for these conditions during that period. These groups comprised:

- Individuals sampled from sectors including: health care, social services, education, manufacturing, engineering, retail, service industries (six focus groups)
Policy implications

- Workers prescribed antidepressants need careful monitoring, especially at the start of treatment, when they may experience side effects which impair their performance at work and pose a risk to safety.

- Employees need accessible patient information, explaining the actions of the medication, potential impact on safety, and what they should expect with regard to symptom improvement.

- Successful rehabilitation requires coordination between managers and staff from occupational health to support workers, and should involve assessment of the risk relating to an individual worker's condition and/or medication with regard to safety in the workplace.

- Individuals attending anxiety management courses run by clinical psychology services in the Midlands. To participate in these courses, participants needed clinical referral from their GPs. Participants in these courses came from various occupational sectors (three focus groups).

A further three focus groups were conducted with staff having responsibility for human resources, personnel, occupational health, and health and safety. The aim of these groups was to examine organisational policy and practice relating to workers with anxiety and depression. The focus groups were conducted at Loughborough University, and at workplace settings throughout the UK.

The results from the 12 groups were then presented to a panel of invited experts. The panel members comprised trades union representatives, practitioners, and researchers in the disciplines of general practice, occupational medicine, health and safety, health and clinical psychology, and psychiatry. The results were presented for discussion and to consider the implications of the findings for work policy and practice.

\section{Research instruments and analyses}

Two focus group interview schedules were developed, one for employees and the other for organisational representatives. Both schedules were piloted and subsequently refined. Each focus group discussion lasted for approximately 90 minutes and was recorded on tape, with the agreement of participants. The recorded material was fully transcribed.

The transcribed data were analysed by the sorting of verbatim material into themes using the method described by Knodel. ${ }^{14}$ The first phase involved physically organising and subdividing data into meaningful segments by cutting and pasting material into categorical collections. The second phase involved determining criteria for organising data into themes (coding the data) and a subsequent search for patterns within themes to draw meaningful conclusions. The initial set of codes (or themes) corresponded to each question in the focus group schedule. In addition, some questions had prompts and a separate code was assigned to each. Other topics arose spontaneously in the discussion (emergent themes) and these were assigned separate codes. The data under each theme was summarised and verbatim quotes used to illustrate the theme being described. The reliability of this analysis was ensured through systematic review of the data by three members of the research team.

This work received approval from the university ethics committee. 
Table 1 Focus group participant details

\begin{tabular}{|c|c|c|c|}
\hline Group & Gender & Employment & Age \\
\hline \multicolumn{4}{|c|}{ Employees with anxiety and depression } \\
\hline Anxiety management group 1 & 8 female & $\begin{array}{l}\text { Secretarial, Sales, Unemployed (2), Photographic assistant, Care assistant, Sales } \\
\text { consultant, Prevocational tutor }\end{array}$ & $18-55$ \\
\hline Anxiety management group 2 & $\begin{array}{l}5 \text { female } \\
2 \text { male }\end{array}$ & $\begin{array}{l}\text { Scientific officer (NHS), Retired (2), Administrator, Veterinary Surgeon, Car } \\
\text { mechanic, Electrician }\end{array}$ & $28-63$ \\
\hline Anxiety management group 3 & $\begin{array}{l}3 \text { male } \\
1 \text { female }\end{array}$ & $\begin{array}{l}\text { Programme Area Manager/Lecturer, Primary School Head Teacher, } \\
\text { Unemployed, Researcher }\end{array}$ & $22-55$ \\
\hline Employee group 1 & $\begin{array}{l}2 \text { female } \\
5 \text { male }\end{array}$ & $\begin{array}{l}\text { Teacher (3), University administrator, Teacher in higher education, } \\
\text { Registrar in primary school, University technician }\end{array}$ & $35-60$ \\
\hline Employee group 2 & 7 female & $\begin{array}{l}\text { Admin in university (2), Bank, Council worker, University administrator, } \\
\text { Enquiry officer-police station, Public sector }\end{array}$ & $29-53$ \\
\hline Employee group 3 & $\begin{array}{l}5 \text { female } \\
2 \text { male }\end{array}$ & $\begin{array}{l}\text { Car leasing-payroll, Food manufacturing, Advisory teacher, Accounts-coach } \\
\text { company, Personnel, Mental Health Social Worker, Freelance Lecturer }\end{array}$ & $30-56$ \\
\hline Employee group 4 (managers) & $\begin{array}{l}3 \text { female } \\
2 \text { male }\end{array}$ & $\begin{array}{l}\text { Front line manager-food company, Personnel manager (NHS), Health } \\
\text { and safety manager (2), Head teacher, Worker in higher education }\end{array}$ & $33-58$ \\
\hline Employee group 5 (managers) & $\begin{array}{l}2 \text { female } \\
3 \text { male }\end{array}$ & $\begin{array}{l}\text { Lawyer in Civil service, Veterinary Surgeon, Deputy governor of prison, } \\
\text { Computing services at university }\end{array}$ & $45-54$ \\
\hline Employee group 6 & $\begin{array}{l}3 \text { female } \\
1 \text { male }\end{array}$ & $\begin{array}{l}\text { Locum staff grade psychiatrist, Consultant psychiatrist, Former GP, } \\
\text { Senior House Officer }\end{array}$ & $28-54$ \\
\hline \multicolumn{4}{|l|}{ Organisational representatives } \\
\hline Organisational group 1 & $\begin{array}{l}1 \text { female } \\
2 \text { male }\end{array}$ & \multirow{3}{*}{\multicolumn{2}{|c|}{$\begin{array}{l}\text { Occupational Health Nurse-manufacturing, Occupational Health Physician-manufacturing, Occupational } \\
\text { Health and Safety Advisor-manufacturing/construction } \\
\text { Training Manager, Hospital Human Resources Manager, Counselling and Support Manager, Human } \\
\text { Resources Manager, Human Resources Advisor-healthcare, Personnel Officer (2) } \\
\text { Occupational Health-manufacturing (3), Union Health and Safety Representative, Health and Safety } \\
\text { Officer-borough council, Occupational Health Nurse-health care (4), Occupational Health Nurse } \\
\text { Specialist-civilian and service employees }\end{array}$}} \\
\hline Organisational group 2 & $\begin{array}{l}5 \text { female } \\
2 \text { male }\end{array}$ & & \\
\hline Organisational group 3 & $\begin{array}{l}7 \text { female } \\
3 \text { male }\end{array}$ & & \\
\hline
\end{tabular}

\section{RESULTS}

Table 1 shows demographic profiles of the participants, both employees with anxiety and depression and organisational representatives $(\mathrm{n}=74)$.

Table 2 lists the psychotropic medication that employees had been prescribed and percentages of respondents that had received each class of drug.

\section{Workers' experiences}

\section{Accidents and near misses}

Participants reported that they found it difficult to distinguish between the effects of the symptoms of anxiety and depression and the effects of their medication. They noted that the symptoms and the side effects of the medication included: confusion, dizziness, and lack of concentration. They believed these side effects/symptoms impaired their ability to function effectively at work and made them more liable to accidents. It was felt that hazards relating to anxiety and depression were difficult to measure in terms of risk assessment as, unlike physical hazards, they are not visible.

Participants described a range of accidents and injuries, which they attributed to their condition or medication.

"I had a series of falls at the time ... I would go faster and faster and faster. If $\mathrm{I}^{\prime} \mathrm{d}$ got a large queve, I'd try and deal with them really quickly and then, because I know they're all waiting I wouldn't take a break. I'd go faster and faster and I'm sure I would walk faster and faster. I had a series of falls and they actually sent me for some tests because of it." (Female working in university administration)

"I tend to make silly mistakes, some of them resulting in cuts, scratches and minor injuries." (Female working in the public sector)

" .... when I went into industry I suffered a hand injury ... it was a hosiery needle that went into my hand and they had to make an incision and take it out and I thought I would be back at work within 2-3 days. It went from bad to worse. The pain was out of this world and I was constantly going to the Infirmary and telling them that something is not quite right here and my absence from work just kept going on." (Male university technician who previously worked in manufacturing)

\section{Accidents while driving}

Driving was an area identified as a high risk activity both at work and when travelling to and from work. A primary school head teacher noticed that his driving was becoming more aggressive and he drove faster because he felt short of time and under pressure to get to work:

"Driving is the thing that I noticed because I was always feeling short of time, under pressure. I have a 25 mile journey to work each day on fairly busy motorways ... my driving was becoming much more aggressive. I was driving a lot faster because I felt that I had to get to work quickly to get going. I couldn't waste a moment of my life even if it meant driving unsafely."

One participant was driving students in a minibus for work and after the journey realised that his mind had not been on the job of driving the bus, though he was not aware of this at the time. Some people felt they were at risk when driving to and from work, because of an inability to concentrate and as a result of tiredness:

"I had one [accident] on my way back from work. I was so highly stressed, and something happened at work, I was quite distracted, I don't normally have accidents, I'm known to be quite a good driver. And somehow, I totally misjudged the amount of space to overtake a car ... it was only wing mirrors that went." (Female teacher) 


\begin{tabular}{|c|c|c|c|}
\hline Drug group & $\begin{array}{l}\% \text { respondents } \\
\text { prescribed this } \\
\text { class of drug }\end{array}$ & Drug & Proprietary name \\
\hline $\begin{array}{l}\text { Selective serotonin } \\
\text { reuptake inhibitors }\end{array}$ & $72 \%$ & $\begin{array}{l}\text { Citalopram } \\
\text { Fluoxetine } \\
\text { Fluvoxamine Maleate } \\
\text { Paroxetine } \\
\text { Sertraline }\end{array}$ & $\begin{array}{l}\text { Cipramil } \\
\text { Prozac } \\
\text { Faverin } \\
\text { Seroxat } \\
\text { Lustral }\end{array}$ \\
\hline Benzodiazepines & $30 \%$ & $\begin{array}{l}\text { Diazepam } \\
\text { Lorazepam } \\
\text { Temazepam }\end{array}$ & $\begin{array}{l}\text { Valium } \\
\text { Ativan }\end{array}$ \\
\hline Antidepressants & $19 \%$ & $\begin{array}{l}\text { Venlaxafine } \\
\text { Mirtazapine } \\
\text { Nefazodone Hydrochloride } \\
\text { Flupentixol }\end{array}$ & $\begin{array}{l}\text { Efexor } \\
\text { Zispin } \\
\text { Dutonin } \\
\text { Fluanxol }\end{array}$ \\
\hline Tricyclics & $9 \%$ & $\begin{array}{l}\text { Imipramine Hydrochloride } \\
\text { Amitriptyline Hydrochloride } \\
\text { Dothiepin Hydrochloride }\end{array}$ & $\begin{array}{l}\text { Tofranil } \\
\text { Lentizol/Triptafen/ } \\
\text { Triptafen-M } \\
\text { Prothiaden }\end{array}$ \\
\hline Anti manic & $6 \%$ & $\begin{array}{l}\text { Doxepin } \\
\text { Lithium Citrate } \\
\text { Lithium Carbonate }\end{array}$ & $\begin{array}{l}\text { Sinequan } \\
\text { Li-Liquid/Priadel } \\
\text { Camcolit/Liskonum/ } \\
\text { Priadel }\end{array}$ \\
\hline Beta blockers & $4 \%$ & $\begin{array}{l}\text { Oxprenolol Hydrochloride } \\
\text { Pindolol }\end{array}$ & $\begin{array}{l}\text { Slow-Trasicor (modified } \\
\text { release) } \\
\text { Trasidrex (with diuretic) } \\
\text { Visken } \\
\text { Viskaldix (with diuretic) }\end{array}$ \\
\hline
\end{tabular}

" ... realising you just don't remember the last five or ten minutes of the journey because you're thinking about something else, on autopilot and certainly I found driving when depressed extremely hard because it's amazing how much concentration levels go down." (Male former GP)

\section{Responsibility for others}

Safety issues particularly concerned individuals who had responsibilities for others, for example, staff with responsibility for health and safety in organisations, teachers, healthcare professionals, and managers:

"One of my responsibilities was to Health and Safety and occasionally I was so tired and fed up with it all, you'd see something but you'd let it go and just not react because, if you did you'd have another load of work." (Male lecturer)

Workers operating machinery felt they were at particular risk. A male electrician said that he took great care when using machinery:

"It is a danger, because if you are suffering from depression or anxiety and you take medication you have to be two pairs of eyes. Careful when using machinery. Because I use a lot of machinery. I have to be very careful."

A car mechanic checked all his work several times, aware that he could endanger someone's life:

"Because I am a foreman and a mechanic, when I do servicing I don't just check the plug once, I check it five times. Then I have to check the wheel nuts five times. Everything is five times. Because you go round it, and you go round it again, 'did I do that?' And then you go round it again. I know other people who don't even suffer with depression probably do that as well. But it is very difficult in our trade. You've got to do it right first time, because you're endangering somebody else's life."

\section{Healthcare professionals}

The healthcare professionals who participated in this study noted that antidepressant use was widespread among their colleagues, as this female consultant psychiatrist who left work for health reasons remarked:

"In the seven years I had been there all three full time female consultants had been off sick with depression, and one of the male consultants had a previous illness of depression. It's happening so much and that's just among consultants, let alone the managers who have been off sick with depression. In fact there was a bit of joke among my team last year, all of us were on antidepressants, we'd just sit down and say 'what are you taking these days?'."

Health professionals, including GPs and hospital doctors believed that they sometimes put themselves and their patients at risk. In some instances, difficulties arising from their symptoms and/or medication resulted in serious consequences:

"That's the worry isn't it, that you're going to make a clinical error. The only complaint I had against me that actually got very far (the relatives took it to the ombudsman, who found eventually for the family) was during a time when I went to my GP and he said 'you should take 5 weeks off sick' and I said 'no I'll be alright'. It was around that time when that person was under my care. I mean the whole total systems failure contributed to it, but I was the consultant in charge of that person's care and I should have made sure that things were done better." (Female locum psychiatrist) 


\begin{abstract}
"My last night at work, I was having one of those days when you can't concentrate. I was just feeling awful. I was asking my house officer to check what I was doing, because I felt she was in a better state than me. We went to an arrest, and it was one of the worst arrests I've ever been to. I made an absolute complete cock up of it and the only sensible thing I said was 'let's stop because I think he's dead anyway' ... but then I got his haematemesis [the vomiting of blood] to my face. I think if I'd been thinking about hepatitis and maybe if $I^{\prime} d$ been feeling a bit better, a little bit more awake, I might have run that arrest better and maybe he wouldn't have vomited blood to my face. I know that night I couldn't concentrate." (Female Senior House Officer)
\end{abstract}

A particular risk was identified in relation to handling hazardous materials, for example, blood, and many doctors were concerned about administering drugs and using needles and in some cases had injured themselves:

"... contact with body fluids is probably the area you are most likely to put yourself at risk apart from driving because I certainly noticed that when I'm not that great it can be very difficult to get blood out of people or get things into people without making a bit of a mess of it. The thing is if you're a psychiatrist like me and you're not doing these things often enough to be proficient, what happens is you forget the routine of having stuff handy. So you don't have the cotton wool, so you're standing there with a needle in somebody's arm and blood goes everywhere, all over you, all over the floor, over the patient and you're apologising and then you're realising 'drug addict, oh goodness knows what they've got'." (Female psychiatrist)

"I certainly remember when I was in general practice, just sometime after I was first ill we had a patient that was known to be AIDS positive and I had to take a blood sample from him at home. I mean normally I had absolutely no problem taking blood samples, it didn't bother me at all and I was quite competent. But now my hands were shaking, whether that would have happened anyway or whether it was a combination of depression and anxiety I don't know. I mean that's one of the things anxiety does, it makes you perceive things as more threatening." (Male former GP)

\section{Organisational perspective}

The focus groups with organisational representatives centred on recruitment, support, and rehabilitation issues for employees with anxiety and depression, as viewed from an organisational perspective.

\section{Recruitment}

Organisational representatives noted that where applicants disclosed a history of anxiety and depression, they might be referred to occupational health departments if there was concern with regard to the work they would have to undertake. This enabled assessment of the work and identification of job modifications if necessary, but it was felt that such assessments were fraught with problems. It takes considerable time to obtain information from health professionals regarding the potential employee's mental health and the employer needs to confirm or withdraw the offer of an appointment quickly in order to be fair to the job applicant. It was suggested that most applicants are reluctant to declare mental health problems because they think it would disadvantage their chances of employment. A male hospital human resources manager commented:

"It's extremely rare that they'll declare that they've got some mental health problem. They're quite happy to declare if they've got a physical problem. I imagine we are employing quite a lot of people who have got a variety of mental health problems that are not known to us when they join the organisation."

\section{Mental health at work}

Organisational representatives felt that the reporting of mental ill health is very problematic for many workers, particularly in male dominated work sectors such as construction and engineering:

"There's this macho image ... some of the people on site are there till seven, eight o'clock in the evening ... if you're in the office at nine o'clock in the evening you're more likely to get promoted. Especially in construction industries, engineering, the macho thing, so that mental health's just brushed under the carpet." (Female health and safety advisor for an engineering and construction firm)

"There's almost some kudos seen in getting a physical injury. Whereas mental illness is seen as a sign of weakness, as someone who's not able to cope." (Male occupational health nurse in heavy industry)

Some workers did not wish to reveal mental health problems such as anxiety and depression to their managers, as a male occupational nurse stated:

"A lot of staff see stress as the kiss of death to their career ... they'll either be first for the redundancy or they'll look at them and say 'Well, if they can't handle their present job without stress, they won't handle a promotion'."

Participants felt that the need to respect a worker's confidentiality sometimes limited the effectiveness of the support that they could provide. A male human resources manager of a hospital explained:

"Employees are often reluctant to have information about
them shared beyond the confines of the Occupational
Health Department. You get advice that the person should
be on lighter duties or should be in a less stressful post and
in practical terms it doesn't actually help you ... to share
any confidence with other managers outside of their
immediate working environment, is quite difficult. They
tend not to want that, they want to keep it close and share
it with as few people as they can. So there is a problem in
achieving the help that you can see they might benefit
from."

Rehabilitation

Various methods of rehabilitation were identified from the wide range of organisations represented. These included phased returns to work involving therapeutic hours over 4-6 weeks, starting with as little as two hours a day. Involvement of managers and colleagues in the rehabilitation plan was considered essential. It was felt that occupational health staff should identify the implications for work of any medication taken by the person returning to work: 
"I think this is one of the important aspects of the Occupational Health role that we identify the medication that people are on and relate that to the job that they are doing. Obviously, if people are operating machinery, driving, that sort of thing, that is one of the main reasons why we see them from a Health and Safety point of view. Our company has a policy that people who're on medicines that may affect their abilities to do the job, have to notify Occupational Health. It is a company requirement people should notify Occupational Health, because psychotropic drugs do affect people's ability to do machinery type jobs." (Male head of nursing from a heavy industry manufacturing company)

It was believed that medical practitioners were concerned about people returning to work too early. Liaison between employers and GPs about rehabilitation programmes would enable some workers to make a phased return to work earlier. As a male head of nursing in a manufacturing company explained:

"GPs are, justifiably, anxious about whether they can let someone come back to work. Because unless they know the employer, and the support they're going to give, then they tend to say 'Well it's all or nothing', you're either better or you're not. We daren't risk letting you go back to work. I think Occupational Health plays a part there, in developing a relationship with local GPs and just giving them the confidence to let their patients come back to work sooner rather than later."

It was noted that employees returning to work on reduced hours should be "extra" to the staff needed, to avoid other workers being put under pressure through having to cover the shortfall. While co-workers might initially show empathy and understanding to those on reduced hours, this feeling may diminish as they continue to carry the extra burden of supporting someone with mental health problems. Employees on reduced hours sometimes returned to full duties too early in order to relieve the pressure on their coworkers.

\section{Validation exercise}

A validation exercise was conducted where the results were presented to an invited group of experts from relevant disciplines to consider the implications for work policy and practice. The participants' views concurred with the findings of the study. They raised the issue that workers were at risk of accidents when they were depressed and not treated with effective medication. They felt that untreated anxiety and depression can be as much a safety risk as any side effects of the medication, as a mental healthcare practitioner remarked:

\section{"In terms of safety there is more risk involved in being depressed and not treated than in being treated effectively on a drug."}

The validation group noted that employment sectors vary in terms of their policies relating to medication. Occupations such as train operation and offshore working have strict policies relating to psychotropic drugs, including alcohol. It was commented that this may deter some operators from notifying their employers that they are taking medication due to the risk of losing their job.

The risks associated with self-medication using alcohol, herbal products, and caffeine were discussed.
Self-medication with herbal products such as St Johns Wort and Rescue Remedy may be used in larger doses than prescribed. Caffeine was also considered to be a problem when used in excess. The use of alcohol was identified as a particular work hazard. As this health care practitioner commented:

\section{"Alcohol is often used as a self-medication. It's not a very effective self-medication. It contributes to the problem. If we don't look for it we are going to be less effective in treating a depression."}

The advantages of maintaining employees with anxiety and depression at work were discussed. Remaining at work maintains a person's social support network. Hence prolonged absence from work due to anxiety and depression is not always beneficial, as noted by a union representative:

"This is a Catch 22 situation. If someone is on medication and they step down from work, you take them away from the problem but you take them away from the social networks."

Validation group respondents described rehabilitation programmes that they had encountered in some organisations that involved a gradual reintroduction of the person back into the organisation. This maintained contact between the person and their colleagues without putting too much pressure on the individual, allowing them to gradually regain their full role in the workplace.

\section{DISCUSSION}

Employees found it difficult to distinguish between the effects of their symptoms and the effects of medication. They felt that both the symptoms and the medication impaired their ability to operate at work and made them more liable to accidents. Generally respondents displayed a high degree of awareness of the impact of the medication and symptoms on their performance and safety at work. Participants described a range of accidents, which they attributed to their condition or medication, including falls, minor injuries, and accidents when driving. Future quantitative studies in this area might usefully focus on reported accidents in the workplace to establish the range and frequency of these incidents.

\section{Employees responsible for the safety and wellbeing of others}

Respondents in occupations having responsibility for others (teachers, healthcare professionals, mechanics, and electricians) felt they were at particular risk with respect to the impact of anxiety and depression and the medication for these conditions on their work. Healthcare professionals considered that they sometimes put themselves and their patients at risk. The risks highlighted by healthcare workers related to impaired clinical judgement, making clinical errors, handling hazardous materials such as blood, administering drugs, and needle injuries.

The experiences described by teachers, managers, and healthcare workers in this study are in line with findings from other quantitative research. A number of studies have indicated that teachers have a high prevalence of anxiety, worry, and fatigue compared to other occupations. ${ }^{15}{ }^{16} \mathrm{~A}$ recent survey of a random population sample, has shown that $20 \%$ reported very high or extremely high levels of stress at work and stress is highest among teachers, nurses, and managers. ${ }^{17-19}$ It would seem there is a strong case for focusing on the mental health of these particular groups of workers, both in terms of future research and policy 
formation. More research is needed to investigate the occupational health of employees with responsibilities for others including: workers in health and social care, managers, and teachers. This work should explore the particular aspects of these occupations that contribute to psychological ill health and determine what organisational factors mediate against the development of mental health problems.

\section{Organisational issues}

Representatives from human resources, personnel, occupational health, and health and safety departments drawn from a wide range of private and public organisations considered the impact of mental health problems and medication on safety in the workplace. They noted that job applicants might be screened in pre-employment questionnaires for previous histories of mental health problems prior to starting work. Where candidates do disclose a history of mental health problems, an assessment may be conducted, but it was felt that candidates were unlikely to disclose such information and that there is probably a high level of unreported psychiatric morbidity in the working population.

Where a person has disclosed a mental health problem to occupational health staff they need to be assured of confidentiality to avoid any potential stigma or discrimination. However, organisational representatives in this study felt that in managing mental health problems at work, occupational health personnel are limited in what can be achieved by the need to respect confidentiality. Organisational representatives felt that improved liaison between GPs and employers could facilitate earlier and more successful rehabilitation of workers with mental health problems. While such liaison may well improve rehabilitation, it would of course necessitate the consent of the patient.

The validation group noted that occupations vary in terms of polices relating to medication. Some organisations, for example, public transport, have very strict policies relating to the use of psychotropic drugs. It was felt this may deter employees from notifying their employers that they are taking medication. Untreated anxiety and depression was also considered to be a safety risk. Self-treatment for anxiety and depression, including the use of alcohol, herbal products, and caffeine were also identified as potential safety risks in the workplace. The level of such self-treatment would be important to establish in future quantitative studies of workplace drug use.

\section{Recommendations}

The results of this study suggest that anxiety and depression and the medication used to treat these conditions may pose a risk to safety in the workplace. Maintaining workers with anxiety and depression at work or rehabilitating workers following sickness absence involves two distinct elements. Firstly, there is the medical judgement about the worker's ability to continue in their job while sick or under a medication regime. Secondly, there is the manager's decision concerning sick leave or modification to work activities for the employee. Occupational health personnel have an important role in representing the employee's interest in this process.

Successful management of mental health problems and rehabilitation requires:

- Coordination between managers and staff from human resources, personnel, occupational health, and health and safety departments to support workers

- Accessible patient information, explaining the actions of the medication, potential impact on safety, and what patients should expect with regard to symptom improvement
- Assessment of the risk relating to an individual worker's condition and/or medication with regard to safety in the workplace

- Flexible working practices to accommodate an employee's capabilities along with careful monitoring and regular review of their workload.

Managers require guidance on maintaining people with anxiety and depression in the workplace, which may involve modifying workloads or the range of tasks workers are asked to undertake. Employers should also provide workers with access to formal and informal counselling services. Managers need support from occupational health, health and safety, human resources, and personnel in the rehabilitation of workers following sick leave for anxiety and depression. Rehabilitation might involve phased return to work, and being excused front line duties such as meetings or dealing with the public until the employee is able to regain their full role in the organisation.

Occupational health staff may need to conduct an assessment of risk relating to medication when the employee returns to work and this should involve liaison with the GP or other health care professionals involved in the treatment of the employee.

\section{Limitations of the study}

This study relied on volunteers' self-report and it is reasonable to assume that employees who had experienced problems with medication may be more likely to participate in such a study than those who had a satisfactory experience. The authors therefore make no claims that these findings can be generalised more widely. Another limitation is that because respondents were directly recruited through workplaces and anxiety and depression management groups, the researchers had no background information on severity of mental health problems of participants. It is likely that occupational risk will vary considerably between those with mild depression and those with more serious depression.

However, this study does provide insight into the problems workers face in managing their symptoms and dealing with the side effects of medication at work. The results indicate that both the symptoms of anxiety and depression and the medication prescribed for these disorders may represent a risk to occupational safety.

\section{Conclusions}

The findings of this work relate directly to the UK Government's occupational health strategy to stop people being made ill by work; help people who are ill return to work; and improve opportunities for people not currently in employment due to ill health. ${ }^{20}$ Prevention of mental health problems, such as anxiety and depression, should be an important goal for organisations both large and small. Early detection and management of mental health problems in the workplace may be achieved through good management and human resource policies being implemented, and through effective communication networks in the organisation. These measures, combined with the careful rehabilitation of workers with anxiety and depression, may offer significant benefits to organisations in terms of reducing accidents, sickness absence, and staff turnover.

\section{ACKNOWLEDGEMENTS}

This work was funded by the UK Health and Safety Executive. The views expressed in this paper are those of the authors and do not necessarily reflect HSE policy. We would like to thank our focus group participants for their support and for the time they gave so generously to this study. 


\section{Authors' affiliations}

C Haslam, Institute of Work, Health \& Organisations, University of

Nottingham, UK

S Atkinson, S Brown, R A Haslam, Health \& Safety Ergonomics Unit, Department of Human Sciences, Loughborough University, UK

Competing interests: none declared

\section{REFERENCES}

1 HSE. Health and safety statistics highlights 2001/02. Sudbury: HSE Books, 2002.

2 Middleton N, Gunnell D, Whitley E, et al. Secular trends in antidepressant prescribing in the UK, 1975-1998. J Public Health Med 2001;23:262-7.

3 Potter WZ. Psychotropic medication and work performance. $J$ Occup Med 1990;32:355-61.

4 Lawrenson RA, Tyrer F, Newson RB, et al. The treatment of depression in UK general practice: selective serotonin reuptake inhibitors and tricyclic antidepressants compared. J Affect Disord 2000;59:149-57

5 Dunne M, Hartley L, Fahey M. Stress, anti-anxiety drugs and work performance. In: Trends in ergonomics of work, 23rd annual conference of the Ergonomics Society of Australia and New Zealand, 1986:170-7.

6 Tilson HH. Medication monitoring in the workplace: toward improving our system of epidemiologic intelligence. J Occup Med 1990;32:313-19.

7 Edwards JG. Depression, antidepressants and accidents. BMJ 1995:311:887-8.

8 Nicholson AN. Medication and skilled work. In: Broadbent DE, Reason J Baddeley A, eds. Human factors and hazardous situations, Proceedings of the
Royal Society Discussion Meeting, 28-29 June 1990. Oxford: Clarendon Press, 1990:65-70

9 Cohen AF, Posner J, Ashby L, et al. A comparison of methods for assessing the sedative effects of diphenhydramine on skills related to car driving. Eur J Clin Pharmacol 1984;27:477-82.

10 DeHart RL. Medication and the work environment. J Occup Med 1990;32:310-19.

11 Mintz J, Mintz LI, Arruda MJ, et al. Treatments of depression and the functional-capacity to work. Arch Gen Psychiatry 1992;49:761-8.

12 American Psychiatric Association. Diagnostic and statistical manual of mental disorders, 4th edn, revised. Washington, DC: APA, 1994.

13 Lader M. Fortnightly review: treatment of anxiety. BMJ 1994;309:321-4.

14 Knodel J. The design and analysis of focus group studies. In: Morgan DL, eds. Successful focus groups: advancing the state of the art. California: Sage Publications, 1993.

15 Cropley M, Steptoe A, Joekes K. Job strain and psychiatric morbidity. Psychol Med 1999;29:1411-16.

16 Travers CJ, Cooper CL. Teachers under pressure. Stress in the teaching profession. London: Routledge, 1996.

17 Smith A. The scale of perceived occupational stress. Occup Med 2000;50:294-8.

18 Smith A, Johal S, Wadsworth E, et al. The scale of occupational stress: the Bristol Stress and Health at Work Study. Sudbury: HSE Books, 2000.

19 Smith A, Brice C, Collins A, et al. The scale of occupational stress: a further analysis of the impact of demographic factors and type of job. Sudbury: HSE Books, 2000.

20 HSC. Securing Health Together. A long term occupational strategy for England, Scotland and Wales. Sudbury: HSE Books, 2000.

\section{bmjupdates+}

bmjupdates+ is a unique and free alerting service, designed to keep you up to date with the medical literature that is truly important to your practice.

bmjupdates+ will alert you to important new research and will provide you with the best new evidence concerning important advances in health care, tailored to your medical interests and time demands.

Where does the information come from?

bmjupdates+ applies an expert critical appraisal filter to over 100 top medical journals A panel of over 2000 physicians find the few 'must read' studies for each area of clinical interest

Sign up to receive your tailored email alerts, searching access and more...

www.bmjupdates.com 